\title{
Structure of human telomeric DNA in crowded solution
}

\author{
Brahim Heddi and Anh Tuân Phan* \\ School of Physical and Mathematical Sciences, Nanyang Technological University, Singapore
}

*Corresponding author: phantuan@ntu.edu.sg

Supporting Information 


\section{SUPPLEMENTARY METHODS}

\section{NMR-restrained structure calculation}

\section{NMR restraints}

Each hydrogen bond was restrained by two distances, which correspond to ideal hydrogen bond geometry: N7-N2 (2.90 $\pm 0.10 \AA), \mathrm{H} 21-\mathrm{N} 7(1.99 \pm 0.10 \AA)$, N1-O6 (2.95 $\pm 0.10 \AA)$, and H1-O6 $(1.95 \pm 0.10 \AA)$. The force constant for hydrogen-bond restraints was kept at 32 kcal.mol ${ }^{-1} . \AA^{-2}$ throughout the computation.

Cross-peaks involving exchangeable and non-exchangeable protons were obtained from the NOESY spectrum in $\mathrm{H}_{2} \mathrm{O}$ (mixing time, $200 \mathrm{~ms}$ ) and in ${ }^{2} \mathrm{H}_{2} \mathrm{O}$ (mixing times, 100, 200 and $300 \mathrm{~ms})$. The peaks were manually classified as strong (1.8-3.8 $\AA$ or $1.5-4.8 \AA$ ), medium (2.8-5.2 $\AA$ ), weak (3.6-6.0 $\AA$ or 3.5-7.5 $\AA$ ) or very weak (4.5-7.5 $)$ ). Heavily overlapped cross-peaks were given a distance of 1.8-7.5 $\AA$. An additional upper bound of $0.5 \AA$ was added for the cross-peaks belonging to a methyl group or for ambiguous proton assignments.

For all guanine residues, glycosidic $\chi$ angles were constrained to $\left(240^{\circ} \pm 60\right)$. To ensure the anti conformation of guanines, the $\mathrm{H} 1^{\prime}-\mathrm{C} 1^{\prime}-\mathrm{N} 9-\mathrm{C} 4$ torsion angles were constrained to $\left(0^{\circ} \pm 60\right)$. Dihedral $\varepsilon$ angles were constrained to $\left(225^{\circ} \pm 75\right)$, which is the usual value observed for G-tetrad cores. These $\varepsilon$ dihedral-angle constraints were supported by the ${ }^{31} \mathrm{P}$ chemical shifts tentatively assigned for guanine residues in the G-tetrad core. Computation performed without these $\varepsilon$ dihedral-angle constraints also gave similar structures.

Planarity restraints were enforced on the base atoms of the G-tetrads.

\section{Distance-geometry simulated annealing}

Extended conformation of the d[TAGGG(TTAGGG) $)_{3}$ ] sequence with ideal geometry was generated randomly using the XPLOR-NIH program. ${ }^{1}$ The extended DNA molecule was then subjected to distance-geometry simulated annealing (DGSA) by using the full set of hydrogen-bond, distance, dihedral, planarity and repulsive restraints. 100 structures were generated and subjected to distance-restrained molecular dynamics in vacuo. 
All 100 DGSA structures were refined with distance-restrained molecular dynamics. The system was heated from $300 \mathrm{~K}$ to $1000 \mathrm{~K}$ in 5 ps and allowed to equilibrate for 1 ps, wherein the force constants for the distance restraints were kept at $2 \mathrm{kcal}_{\mathrm{mol}}{ }^{-1} . \AA^{-2}$. The force constants for non-exchangeable proton, exchangeable proton, and repulsive distance restraints were then scaled to final values of 16,8 and $16 \mathrm{kcal} . \mathrm{mol}^{-1} . \AA^{-2}$, respectively, in $26 \mathrm{ps}$. Subsequently, the system was slowly cooled down to $300 \mathrm{~K}$ in 14 ps, after which equilibration was performed for another $10 \mathrm{ps}$. Coordinates of the molecule were saved every $0.5 \mathrm{ps}$ during the last $4.0 \mathrm{ps}$ and averaged. In the final step, the average structure was subjected to minimization until the gradient of energy was less than $0.1 \mathrm{kcal}^{\mathrm{mol}}{ }^{-1}$. Dihedral $\left(50 \mathrm{kcal} \cdot \mathrm{mol}^{-1} \cdot \mathrm{rad}^{-2}\right)$ and planarity $\left(1 \mathrm{kcal} \cdot \mathrm{mol}^{-1} . \AA^{-2}\right)$ restraints were maintained throughout the course of the refinement. 10 best structures with the lowest overall energy were selected for further refinement in explicit solvent.

\section{Molecular dynamics refinement in explicit solvent}

The 10 best structures from in vacuo structure calculation were refined with distancerestrained molecular dynamics simulations in explicit solvent using the program AMBER $10.0^{2}$ with the force field ParmBSC0. ${ }^{3}$ The system was neutralized by $22 \mathrm{~K}^{+}$ions (two of them were in the center of the G-tetrad core) and solvated with 8074 water molecules $(\mathrm{TIP} 3 \mathrm{P})^{4}$ in a truncated octahedral box. Simulations were performed with periodic boundary conditions at constant temperature $\left(27^{\circ} \mathrm{C}\right)$ and pressure ( 1 bar) using the Berendsen coupling scheme. ${ }^{5}$ Covalent bonds involving hydrogens were restrained using the SHAKE algorithm ${ }^{6}$ with integration time-step of 2 fs. Long-range electrostatic interactions were treated using the particle mesh Ewald (PME) approach with a $9 \AA$ direct space cut-off applied to the LennardJones interactions. The non-bonded pair list was updated heuristically and the center-of-mass motion removed every $10 \mathrm{ps.}$

Hydrogen bond and distance restraints were imposed throughout the course of the refinement (200 ps). The water molecules and counterions were energy-minimized and equilibrated around the fixed DNA for 100 ps in the NVT (at constant volume and temperature) ensemble; the entire system was initially relax with 1000 steps of minimization (500 steps of steepest descent minimization followed by 500 steps of conjugate gradient). The system was then heated from 100 to $300 \mathrm{~K}$ in 10 ps with harmonic positional restraints on the DNA atoms (force constant of $25.0 \mathrm{kcal} / \mathrm{mol} / \AA^{2}$ ), which were gradually removed over the $100 \mathrm{ps}$. The 
simulation was then continued in NPT (at constant pressure and temperature) for another 100 ps. The lowest energy structure from the last 100 final frames of each trajectory was taken as representative structures. Each structure was then subjected to energy minimization until the gradient of energy was less than $0.1 \mathrm{kcal}_{\mathrm{mol}}{ }^{-1}$.

\section{Computation solvent distribution}

Molecular dynamics simulations with a mixed water/ethanol solvent were run with similar parameters to that of the molecular dynamics refinement in explicit water, except that the solvent molecules were energy-minimized and equilibrated around the fixed DNA for 500 ps in the NVT (at constant volume and temperature) ensemble. The system was neutralized by $22 \mathrm{~K}^{+}$cations (two of them were in the center of the G-tetrad core) and solvated with 5551 water molecules (TIP3P) and $1930 \mathrm{EtOH}$ molecules in a truncated octahedral box. The volume occupied by ethanol was set to $40 \%$ of the total volume assuming an experimental density of $0.789 \mathrm{~g} / \mathrm{cm}^{3}$ for ethanol and $0.998 \mathrm{~g} / \mathrm{cm}^{3}$ for water. 


\section{SUPPLEMENTARY TABLES}

Table S1. List of site-specific modified sequences used for NMR spectral assignments

\begin{tabular}{|c|c|}
\hline Туре & $\begin{array}{c}\text { Sequence } \\
5,-3,\end{array}$ \\
\hline${ }^{15} \mathrm{~N}-\mathrm{l}$ & 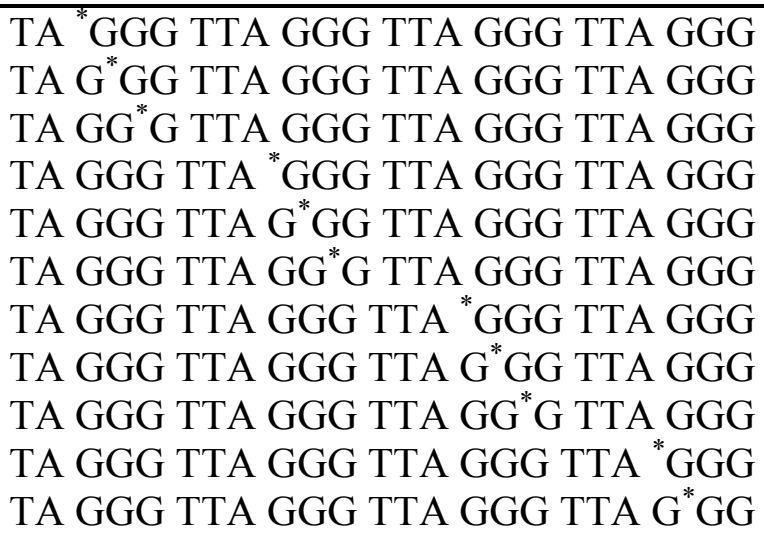 \\
\hline${ }^{2} \mathbf{H}-\mathbf{l}$ & 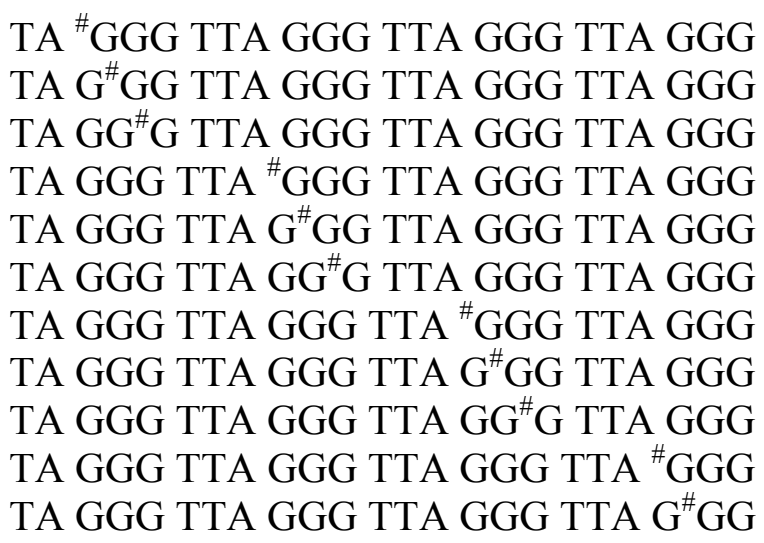 \\
\hline U-substituted & TA GGG UTA GGG UTA GGG UTA GGG \\
\hline
\end{tabular}

(a) Guanines marked with asterisks were $2 \%{ }^{15} \mathrm{~N}$-labeled

(b) Guanines marked with hash signs were deuterated at the $\mathrm{H} 8$ position

(c) Modified nucleotides are in boldface; $U$ is uracil 


\section{SUPPLEMENTARY FIGURES}

Figure S1. Three dimensional (top) and schematic structures (bottom) of intramolecular Gquadruplexes formed by human telomeric sequences: (A) basket-type G-quadruplex observed by NMR for the sequence d[AGGG(TTAGGG) $)_{3}$ ] in $\mathrm{Na}^{+}$-containing solution (PDB ID: 143D); (B), (3+1) Form 1 G-quadruplex observed by NMR for the sequence d[TAGGG(TTAGGG) $)_{3}$ ] in $\mathrm{K}^{+}$-containing dilute solution (PDB ID: $\left.2 \mathrm{JSM}\right) ;^{8}(\mathrm{C}),(3+1)$ Form 2 G-quadruplex observed by NMR for the sequence d[TAGGG(TTAGGG) ${ }_{3} \mathrm{TT}$ ] in $\mathrm{K}^{+}-$ containing dilute solution (PDB ID: $2 \mathrm{JSC}) ;^{8}$ (D), basket-type G-quadruplex with two G-tetrad layers observed by NMR for the sequence d[GGG(TTAGGG) $\left.{ }_{3} \mathrm{~T}\right]$ in $\mathrm{K}^{+}$-containing dilute solution (PDB ID: $2 \mathrm{KF} 8) ;^{9}$ (E), chair-type G-quadruplex observed by NMR for the sequence $\mathrm{d}\left[\mathrm{AGGG}(\mathrm{CTAGGG})_{3}\right]$ in $\mathrm{K}^{+}$-containing dilute solution (PDB ID: $\left.2 \mathrm{KM} 3\right)^{10}{ }^{10}$ and (F), propeller-type G-quadruplex observed for the sequence d[AGGG(TTAGGG) $)_{3}$ ] in a $\mathrm{K}^{+}$containing crystal (PDB ID: 1KF1). ${ }^{11}$ Anti guanines are colored cyan; syn guanines, magenta; cytosines, brown; and TTA linkers, red.

Figure S2. CD spectra of the Htelo2 sequence in dilute solution (blue), and in the presence of $20 \%(\mathrm{v} / \mathrm{v})($ green), 30\% (v/v) (magenta), and $40 \%$ (v/v) (red) of (A) PEG 200, (B) ethanol, (D) acetonitrile; and in the presence of $200 \mathrm{~g} / \mathrm{L}$ (green), $300 \mathrm{~g} / \mathrm{L}$ (magenta) and $400 \mathrm{~g} / \mathrm{L}$ (red) of (C) PEG 8000 and (E) PEG 35000.

Figure S3. CD spectra of the Htelo3 sequence in dilute solution (blue), and in the presence of $20 \%(\mathrm{v} / \mathrm{v})($ green), 30\% (v/v) (magenta), and $40 \%$ (v/v) (red) of (A) PEG 200, (B) ethanol, (D) acetonitrile; and in the presence of $200 \mathrm{~g} / \mathrm{L}$ (green), $300 \mathrm{~g} / \mathrm{L}$ (magenta) and $400 \mathrm{~g} / \mathrm{L}$ (red) of (C) PEG 8000 and (E) PEG 35000.

Figure S4. CD spectra of the Htelo4 sequence in dilute solution (blue), and in the presence of $20 \%(\mathrm{v} / \mathrm{v})($ green), 30\% (v/v) (magenta), and $40 \%(\mathrm{v} / \mathrm{v})(\mathrm{red})$ of (A) PEG 200, (B) ethanol, (D) acetonitrile; and in the presence of $200 \mathrm{~g} / \mathrm{L}$ (green), $300 \mathrm{~g} / \mathrm{L}$ (magenta) and $400 \mathrm{~g} / \mathrm{L}$ (red) of (C) PEG 8000 and (E) PEG 35000.

Figure S5. NMR imino proton spectra of Htelol in dilute solution (bottom, reference) and in crowded solution induced by (A) 40\% (v/v) (top) and 30\% (v/v) (middle) of PEG 200, (B) $40 \%(\mathrm{v} / \mathrm{v})($ top) and 30\% (v/v) (middle) of ethanol, (C) 40\% (v/v) (top) and $30 \%(\mathrm{v} / \mathrm{v})$ (middle) of acetonitrile.

Figure S6. NMR imino proton spectra of Htelo1 in (A) dilute solution (reference) and (B) a mixture of $20 \%$ (v/v) PEG 200 and 20\% (v/v) acetonitrile.

Figure S7. NMR imino proton spectra of Htelol in (A) dilute solution (reference), (B) 200 $\mathrm{g} / \mathrm{L}$ of Ficoll 400, and (C) a mixture of 20\% (v/v) PEG 200 and $200 \mathrm{~g} / \mathrm{L}$ Ficoll 400.

Figure S8. Time-dependent CD spectra of Htelol following addition of $40 \%$ (v/v) PEG 200 at (A) $35^{\circ} \mathrm{C}$, (B) $55^{\circ} \mathrm{C}$, and (C) $65^{\circ} \mathrm{C}$. (D) The $290-\mathrm{nm}$ peak intensity as a function of time at different temperatures. Time-dependant CD spectra of the Htelol sequence following 100fold dilution of a PEG-containing concentrated DNA sample at (A) $35^{\circ} \mathrm{C}$, (B) $55^{\circ} \mathrm{C}$, and (C) $65^{\circ} \mathrm{C}$. $(\mathrm{H})$ The $290-\mathrm{nm}$ peak intensity as a function of time at different temperatures. Spectra were recorded with a time interval of 13 seconds.

Figure S9. Imino protons of Htelol in crowded condition were assigned in ${ }^{15} \mathrm{~N}$-filtered 
spectra of samples, $2 \%{ }^{15} \mathrm{~N}$-labeled at the indicated position. The reference spectrum is shown at the top.

Figure S10. Assignment of NOE cross peaks involving G4(H8) by site-specific deuteration. Superposition of 2D NOESY spectra (mixing time, $300 \mathrm{~ms}$ ) of Htelol with and without sitespecific deuteration in crowded solution: (A) H8/6-H8/6 region, (B) H1'-H8/6 region, and (c) $\mathrm{H} 3$ '-H8/6 region. Reference spectrum is colored in black; the spectrum of sample with deuteration at the G4(H8) position is shown in red. Arrows indicate the peaks that disappear in the red spectrum.

Figure S11. Assignment of NOE cross peaks involving G5(H8) by site-specific deuteration. Superposition of 2D NOESY spectra (mixing time, $300 \mathrm{~ms}$ ) of Htelol with and without sitespecific deuteration in crowded solution: (A) H8/6-H8/6 region, (B) H1'-H8/6 region, and (c) H3'-H8/6 region. Reference spectrum is colored in black; the spectrum of sample with deuteration at the G5(H8) position is shown in red. Arrows indicate the peaks that disappear in the red spectrum.

Figure S12. Assignment of thymines by site-specific T-to-U substitutions. Superposition of the $\mathrm{CH}_{3}-\mathrm{H} 8 / 6$ region of 2D NOESY spectra (mixing time, $300 \mathrm{~ms}$ ) of Htelol and a sitespecific modified sequence in crowded solution. Reference spectrum is shown in black; the spectrum of the DNA sequence with T-to-U substitutions at positions 6,12 and 18 is shown in red. The arrow indicates the peaks that disappear in the red spectrum.

Figure S13. Solvent exchange experiment for Htelo1 in crowded solution induced by $40 \%$ (v/v) PEG 200. Exchange of imino protons with solvent was followed by recording spectra before and at $2 \mathrm{~h}$ after dissolving the sample in ${ }^{2} \mathrm{H}_{2} \mathrm{O}$.

Figure S14. Representative NMR-derived structure of the T1-A2-G3 fragment. The dashed lines represent the inter-proton distances observed in NOESY spectra.

Figure S15. Representative NMR-derived structure of the T6-T7-A8 loop. The dashed lines represent the inter-proton distances observed in NOESY spectra.

Figure S16. Crystal packing observed in the X-ray structure (PDB ID: $1 \mathrm{KF} 1)^{11}$ showing (A) loop-loop interactions and (B and C) loop-G-tetrad interactions between symmetry-related molecule in the crystal lattice.

Figure S17. Molecular dynamics simulation of solvent distribution for the propeller-type parallel-stranded G-quadruplex. Time evolution of the distribution of ethanol molecules calculated from 3 to $6 \AA$ around the G-quadruplex. The system was equilibrated after $\sim 1.5 \mathrm{~ns}$ of simulation. Similar results were obtained for the $(3+1)$ G-quadruplex.

Figure S18. NMR imino proton spectra of Htelo3 in (A) dilute solution (reference), (B) in 30\% (v/v) PEG 200, and (C) 40\% (v/v) PEG 200.

Figure S19. NMR imino proton spectra of Htelol in (A) dilute solution (reference), (B) in 40\% (v/v) PEG 200, and (C) 50\% (v/v) PEG 200.

Figure S20. NMR imino proton spectra of Htelo2 in (A) dilute solution (reference), (B) in 40\% (v/v) PEG 200, (C) in 50\% (v/v) PEG 200, and (D) in 60\% (v/v) PEG 200. 
Figure S21. NMR imino proton spectra of (A) Htelo3 and (B) a Htelo3 modified sequence with an additional adenine at the 5' end in dilute solution (reference) and in the presence of $40 \%(\mathrm{v} / \mathrm{v})$ PEG 200. 


\section{REFERENCES}

(1) Schwieters, C. D.; Kuszewski, J. J.; Tjandra, N.; Clore, G. M. J. Magn. Reson. 2003, 160, 65 .

(2) Case, D. A.; Cheatham, T. E., 3rd; Darden, T.; Gohlke, H.; Luo, R.; Merz, K. M., Jr.; Onufriev, A.; Simmerling, C.; Wang, B.; Woods, R. J. J. Comput. Chem. 2005, 26, 1668.

(3) Perez, A.; Marchan, I.; Svozil, D.; Sponer, J.; Cheatham, T. E., 3rd; Laughton, C. A.; Orozco, M. Biophys J. 2007, 92, 3817.

(4) Jorgensen, W. L.; Chandrasekhar, J.; Madura, J. D.; Impey, R. W.; Klein, M. L. J. Chem. Phys. 1983, 79, 926.

(5) Berendsen, H. J. C.; Postma, J. P. M.; Vangunsteren, W. F.; Dinola, A.; Haak, J. R. J. Chem. Phys. 1984, 81, 3684.

(6) Vangunsteren, W. F.; Berendsen, H. J. C. Mol. Phys. 1977, 34, 1311.

(7) Wang, Y.; Patel, D. J. Structure 1993, 1, 263.

(8) Phan, A. T.; Kuryavyi, V.; Luu, K. N.; Patel, D. J. Nucleic Acids Res. 2007, 35, 6517.

(9) Lim, K. W.; Amrane, S.; Bouaziz, S.; Xu, W.; Mu, Y.; Patel, D. J.; Luu, K. N.; Phan, A. T. J. Am. Chem. Soc. 2009, 131, 4301.

(10) Lim, K. W.; Alberti, P.; Guedin, A.; Lacroix, L.; Riou, J. F.; Royle, N. J.; Mergny, J. L.; Phan, A. T. Nucleic Acids Res. 2009, 37, 6239.

(11) Parkinson, G. N.; Lee, M. P.; Neidle, S. Nature 2002, 417, 876. 
Figure S1

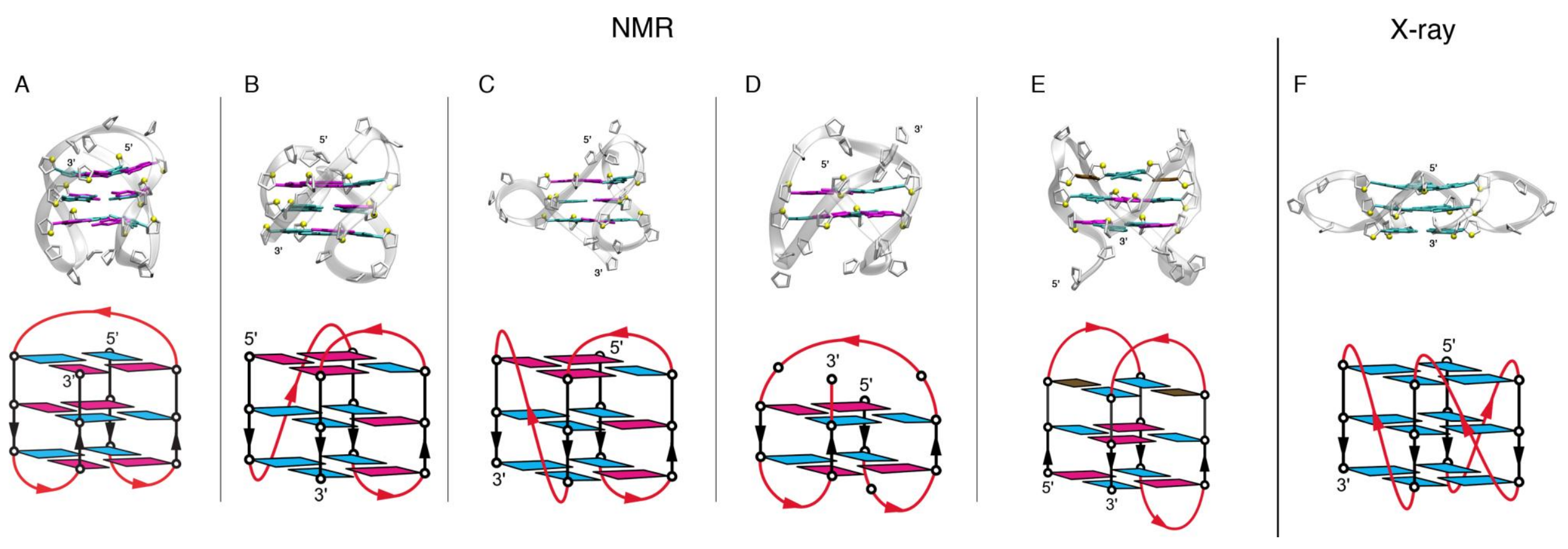


Figure S2

\section{d[TAGGG(TTAGGG) ${ }_{3}$ TT]}
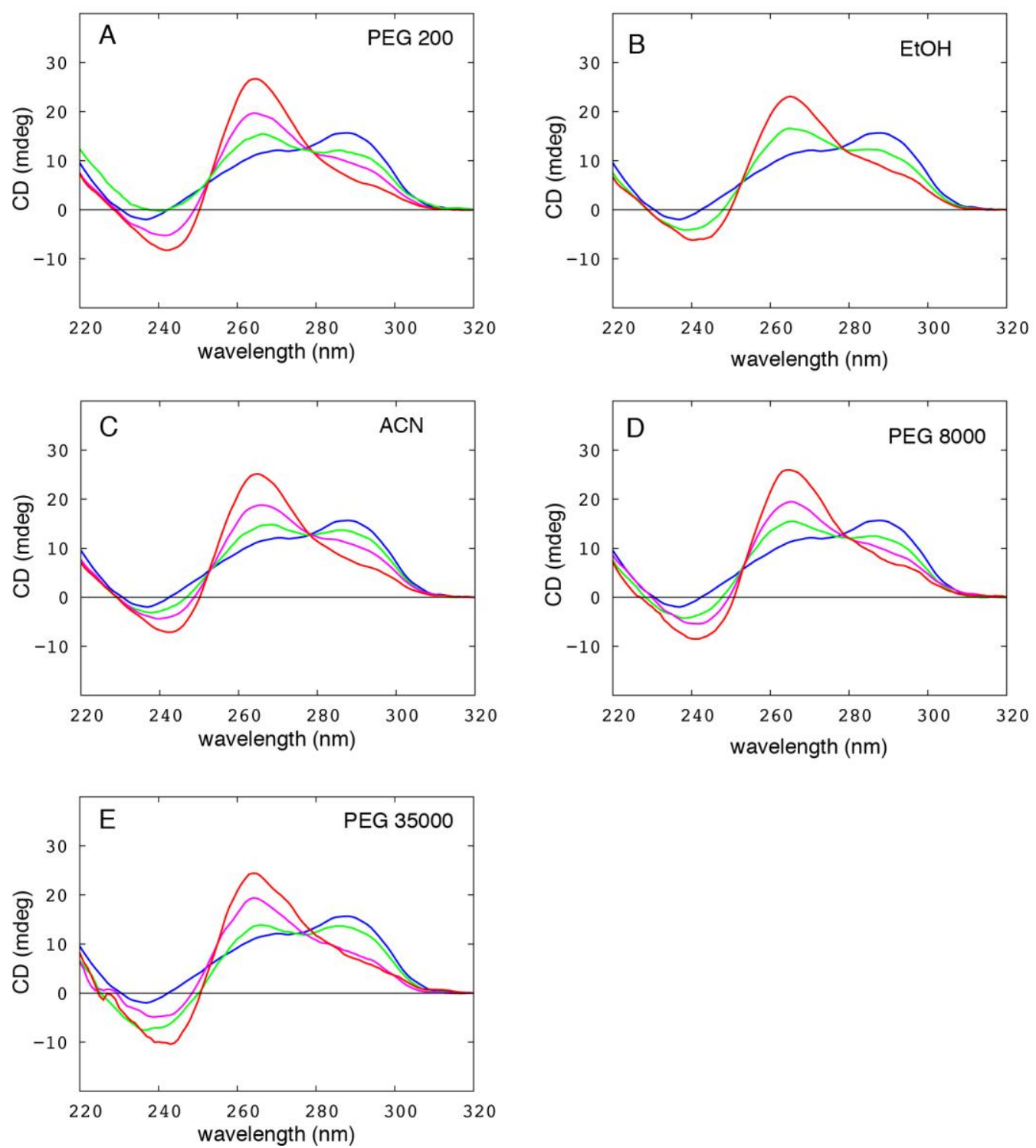
Figure S3

\section{$\mathrm{d}\left[\mathrm{GGG}(\mathrm{TTAGGG})_{3} \mathrm{~T}\right]$}
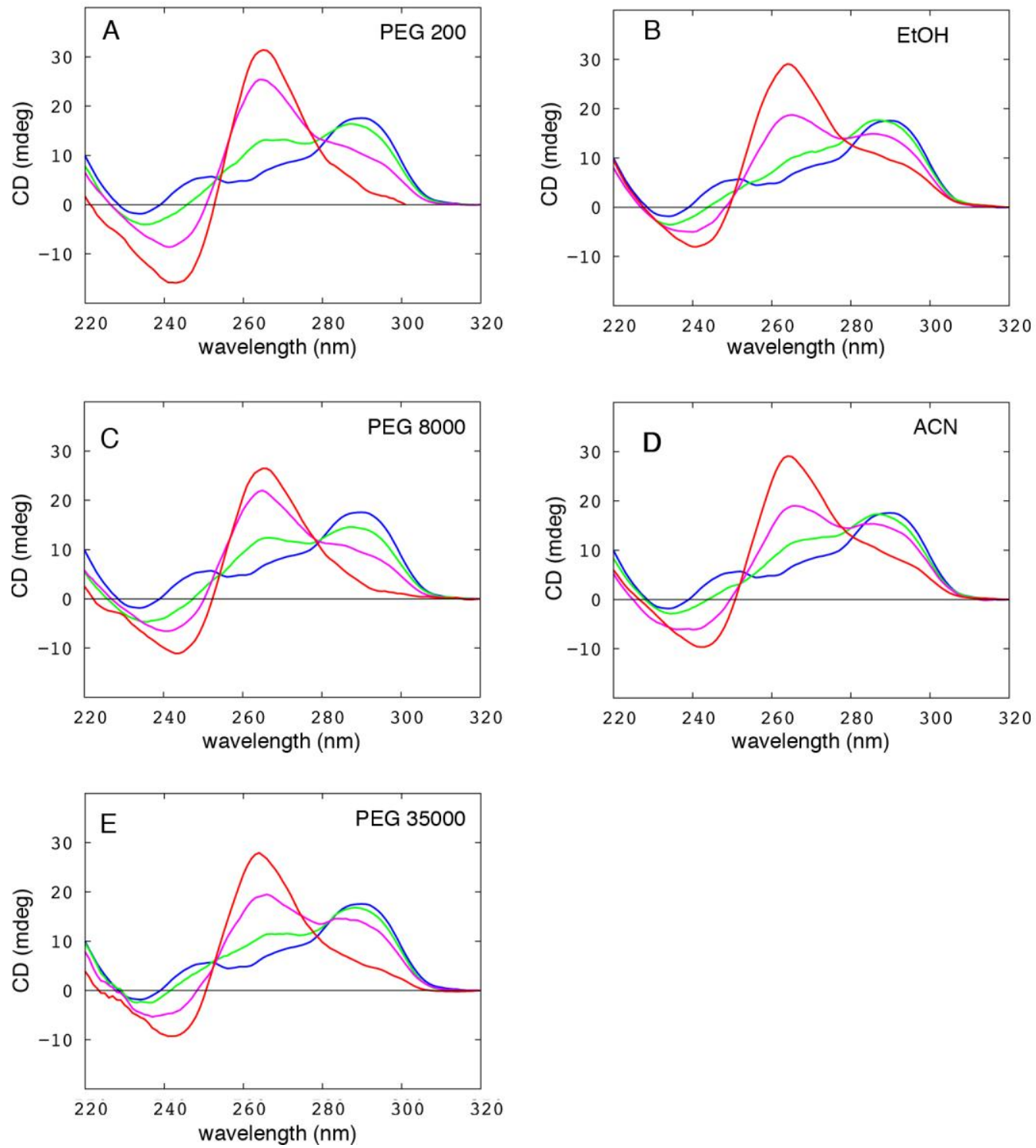
Figure S4

\section{$\mathrm{d}\left[\mathrm{AGGG}(\mathrm{CTAGGG})_{3}\right]$}
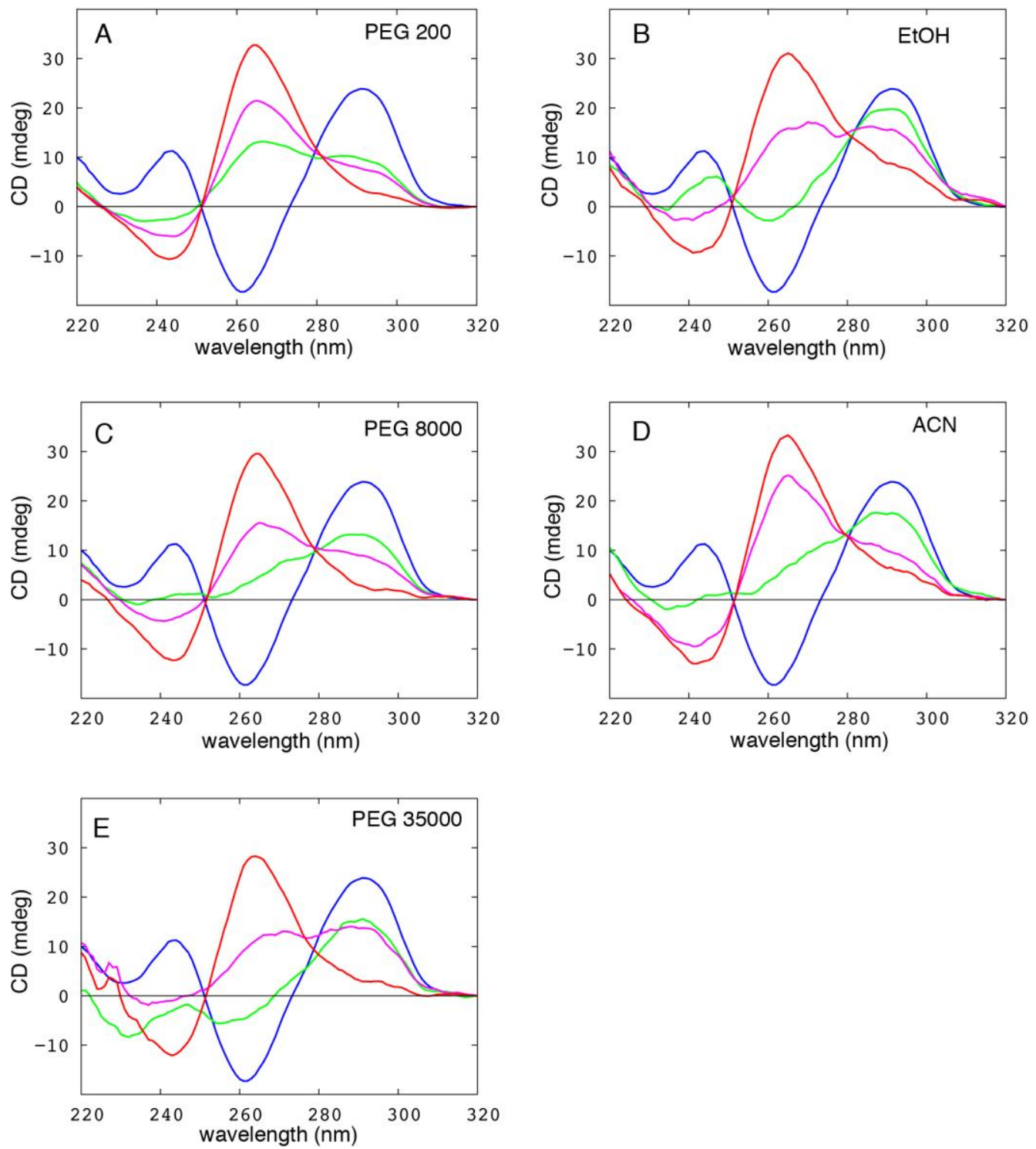
Figure S5

PEG 200

A
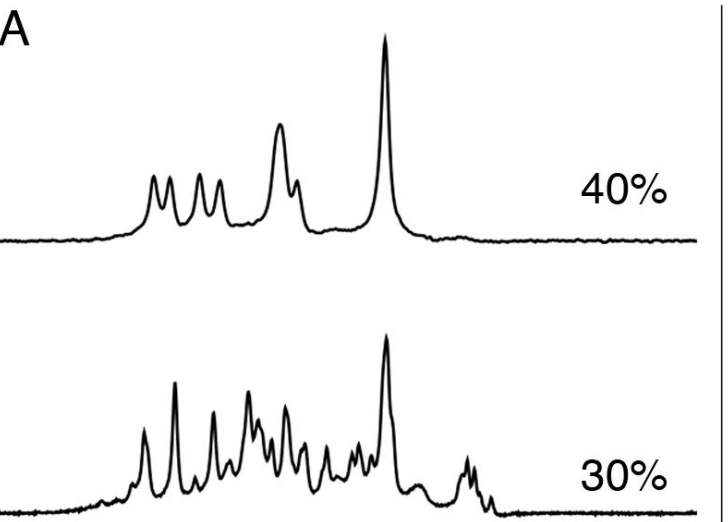

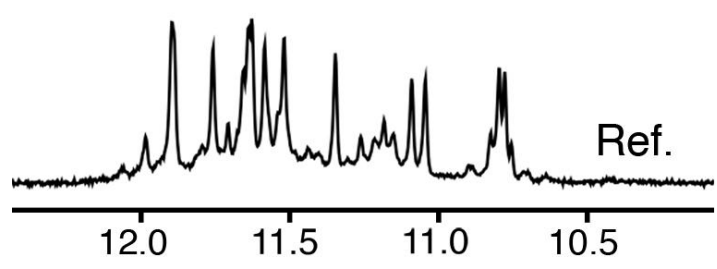

$\mathrm{EtOH}$

B

MUMa

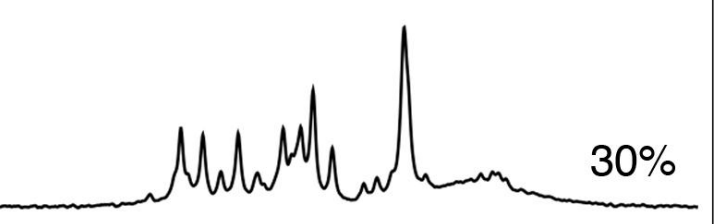

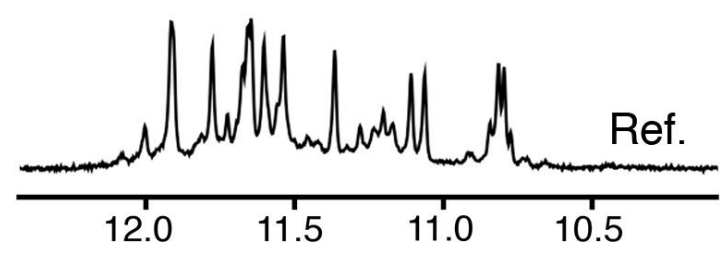

ACN

C

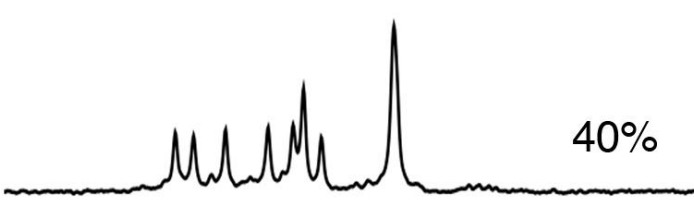

MMMr hor 30\%

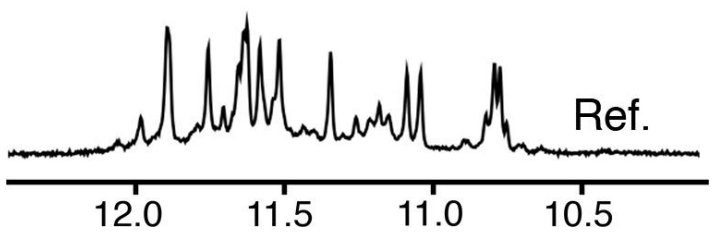


Figure S6
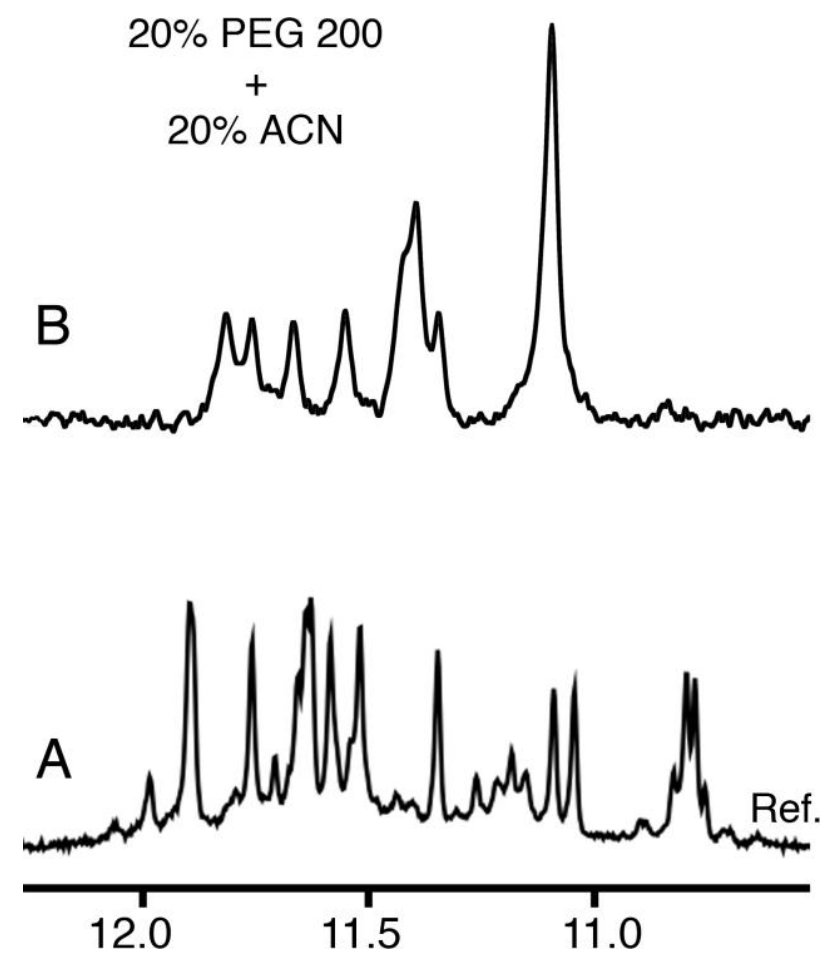
Figure S7

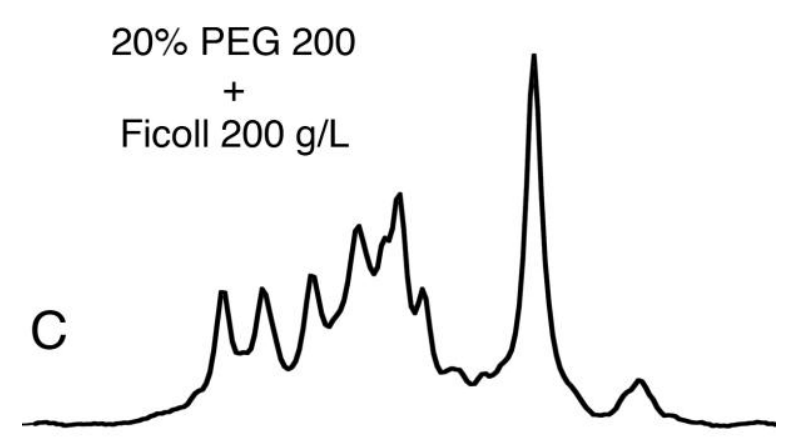

Ficoll $200 \mathrm{~g} / \mathrm{L}$
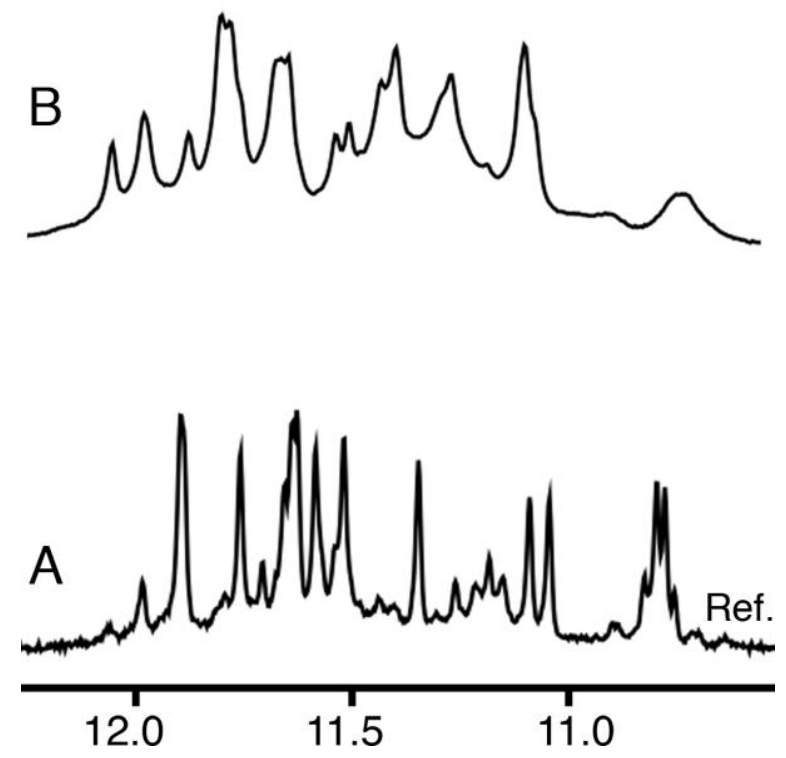
Figure S8
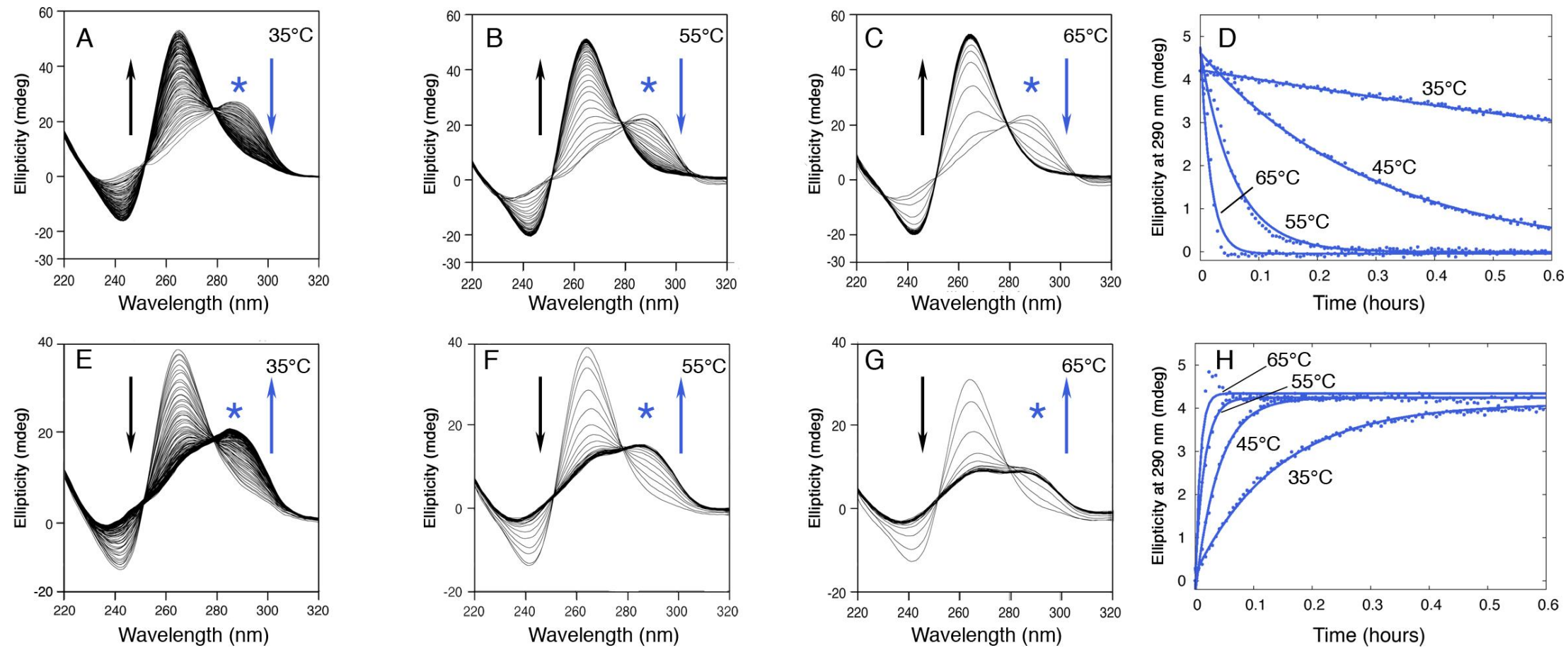
Figure S9
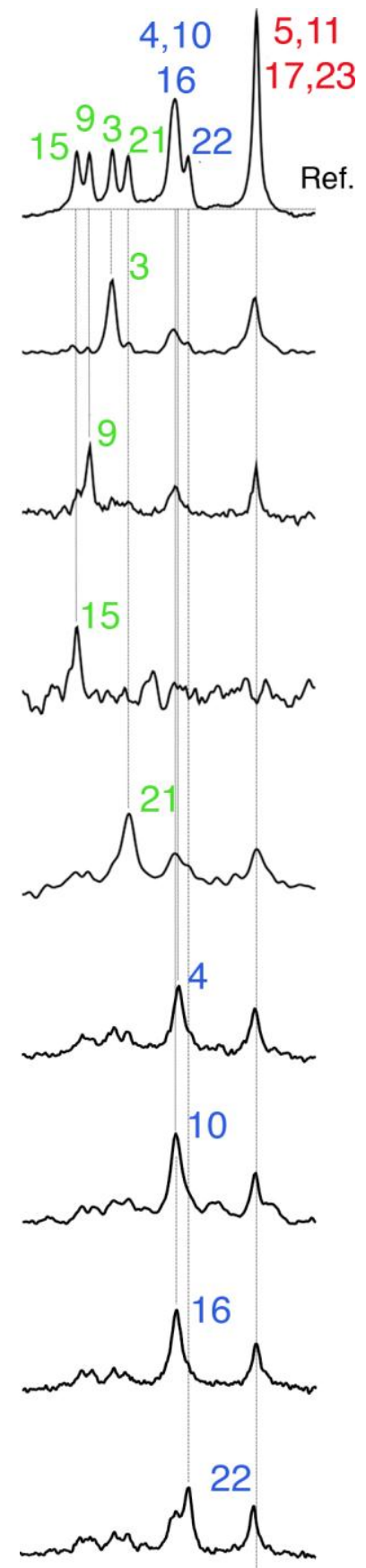

12.0 11.5 11.0 
Figure S10
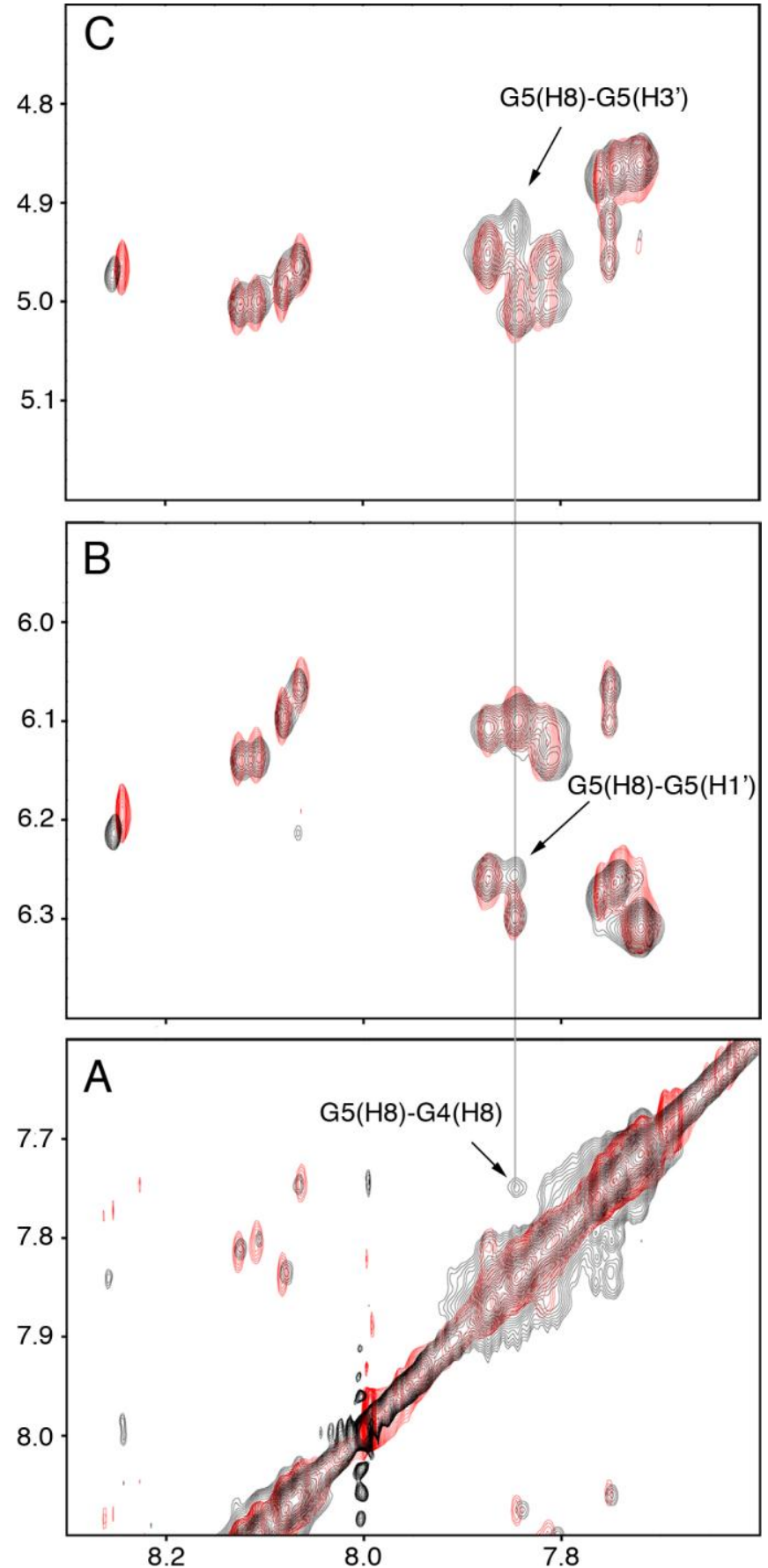
Figure S11
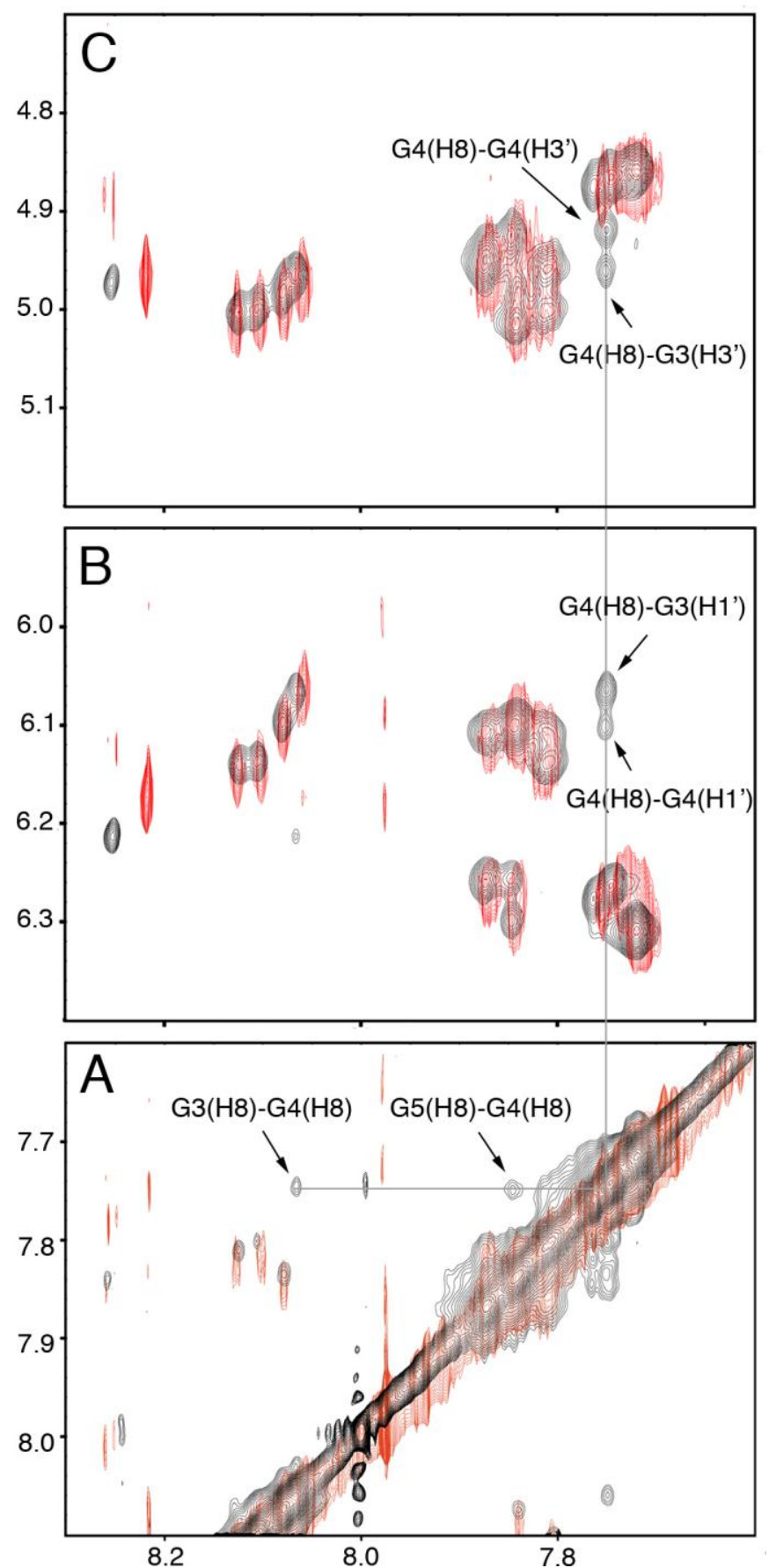
Figure S12

$\left.\mathrm{d}[\text { TAGGG(TTAGGG) })_{3}\right]$
$\mathrm{d}\left[\right.$ TAGGG(UTAGGG) $\left.{ }_{3}\right]$

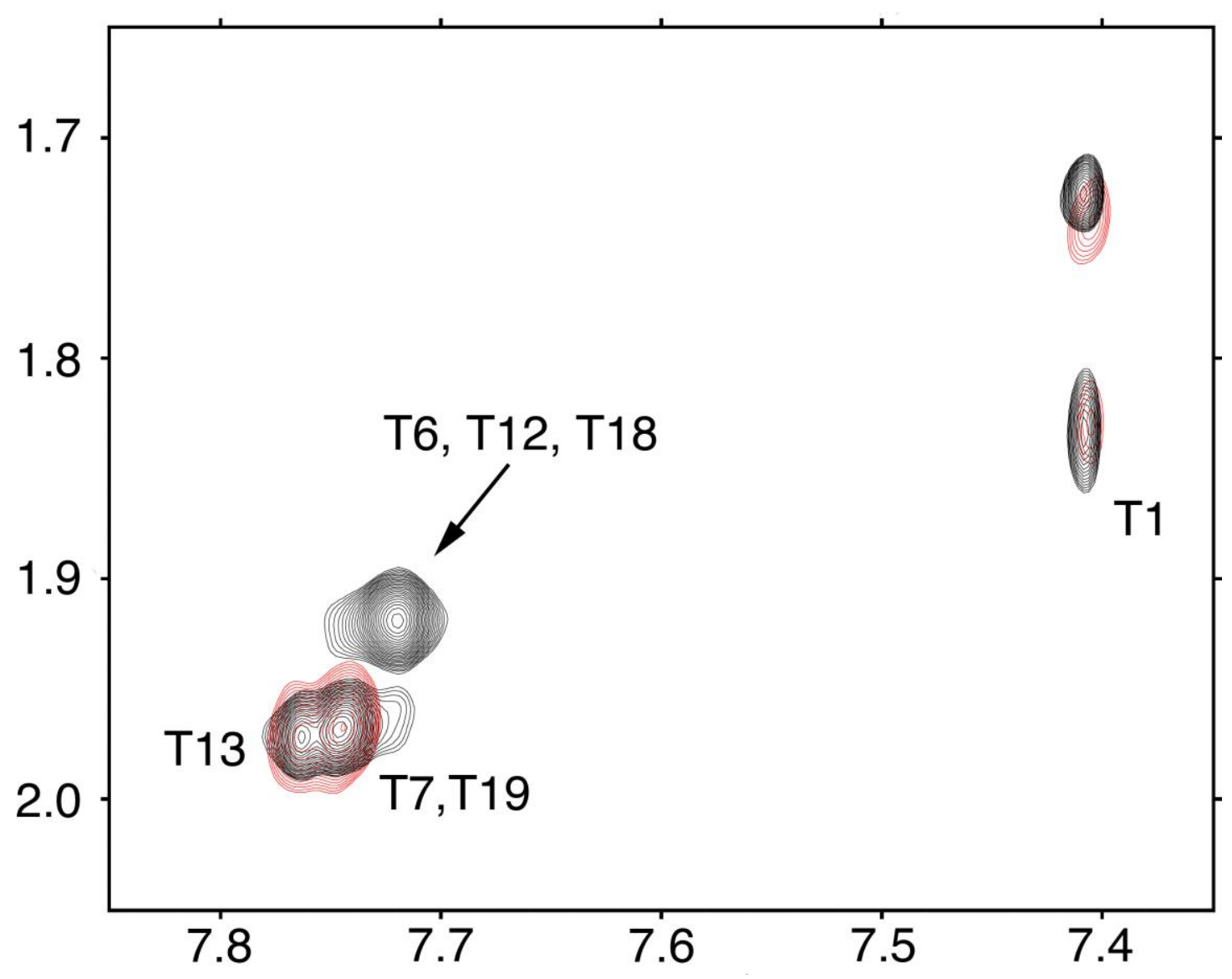


Figure S13

\section{d[TAGGG(TTAGGG) ${ }_{3}$ ] 40\% v/v PEG 200}
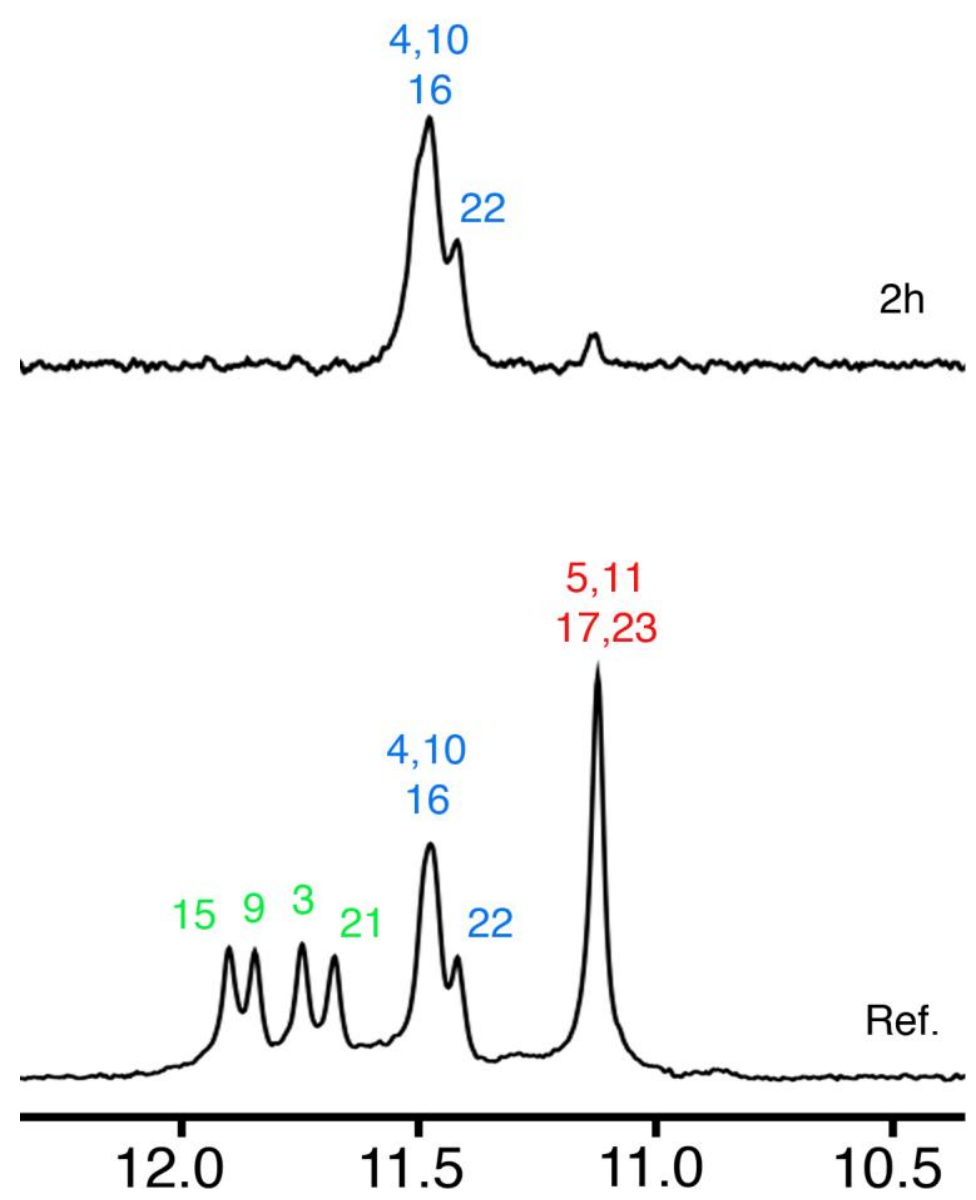
Figure S14

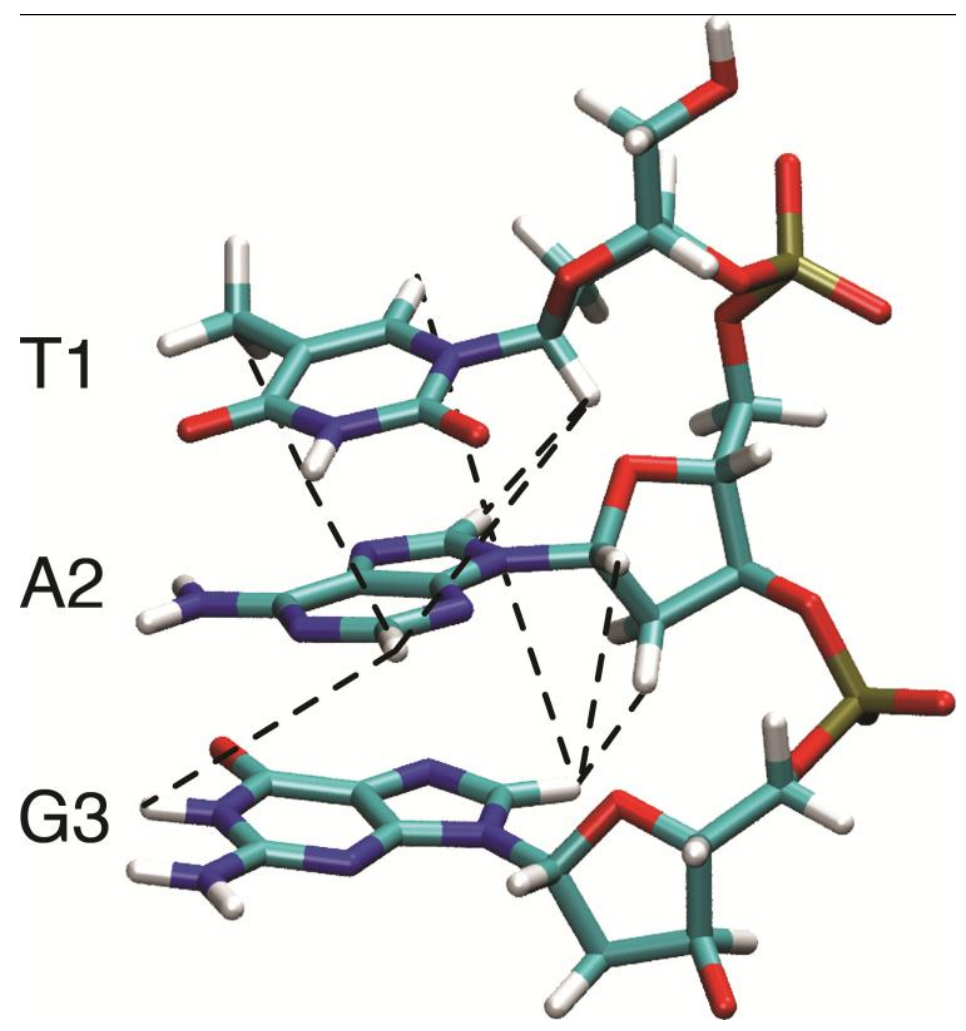


Figures S15

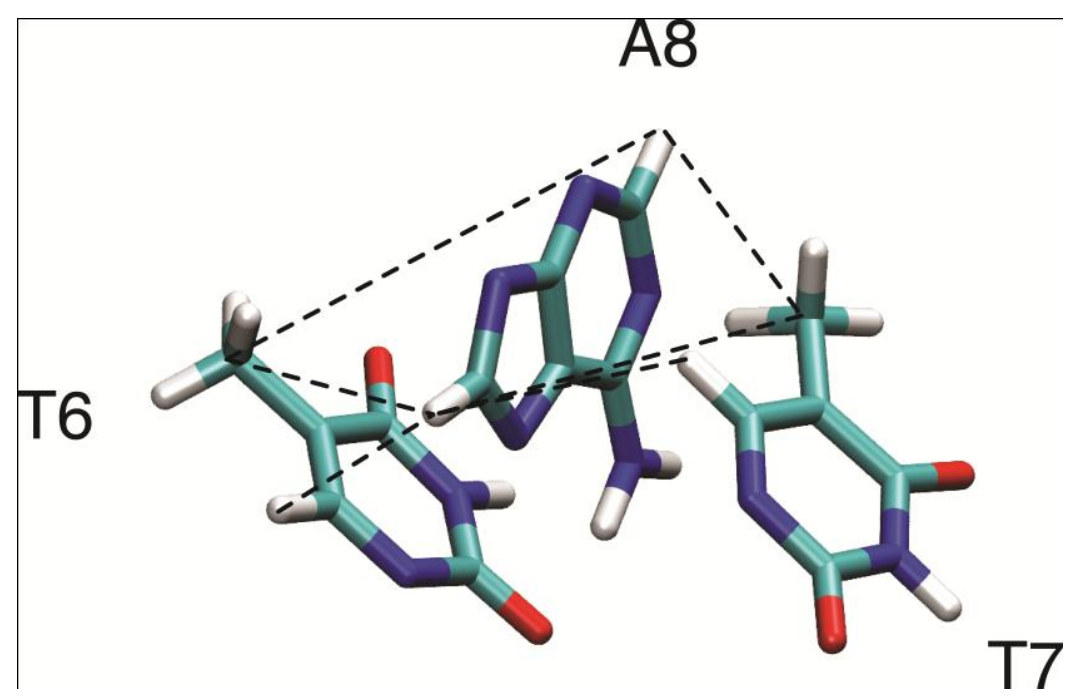


Figure S16

A

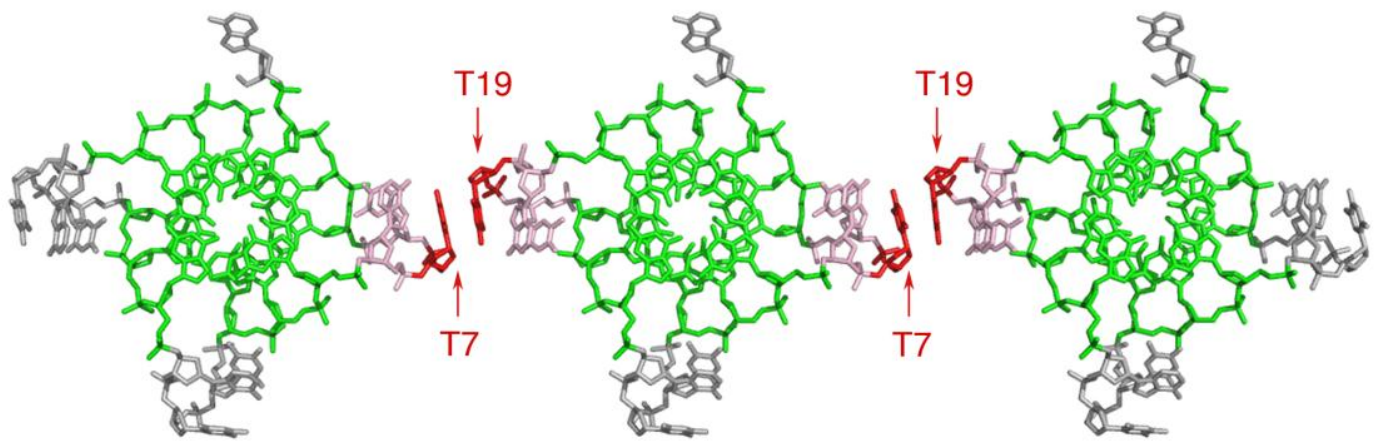

B

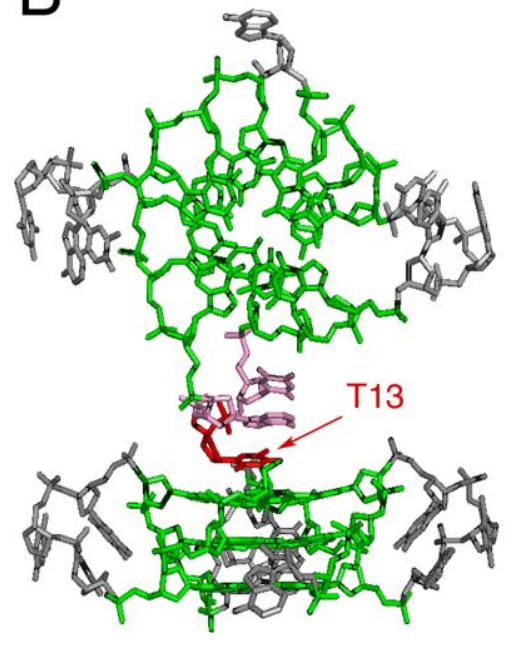

C

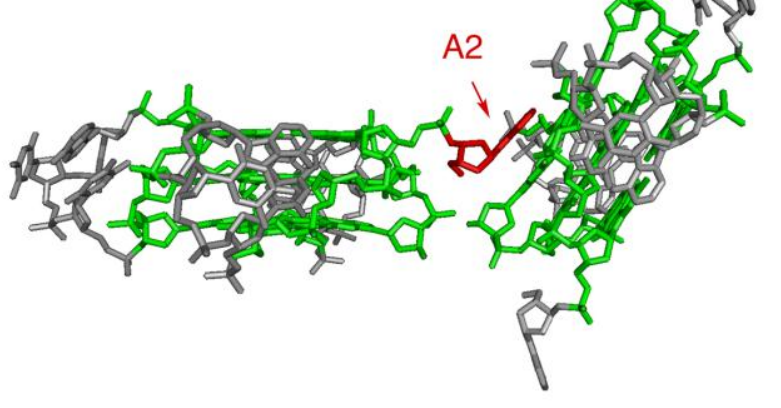


Figure S17

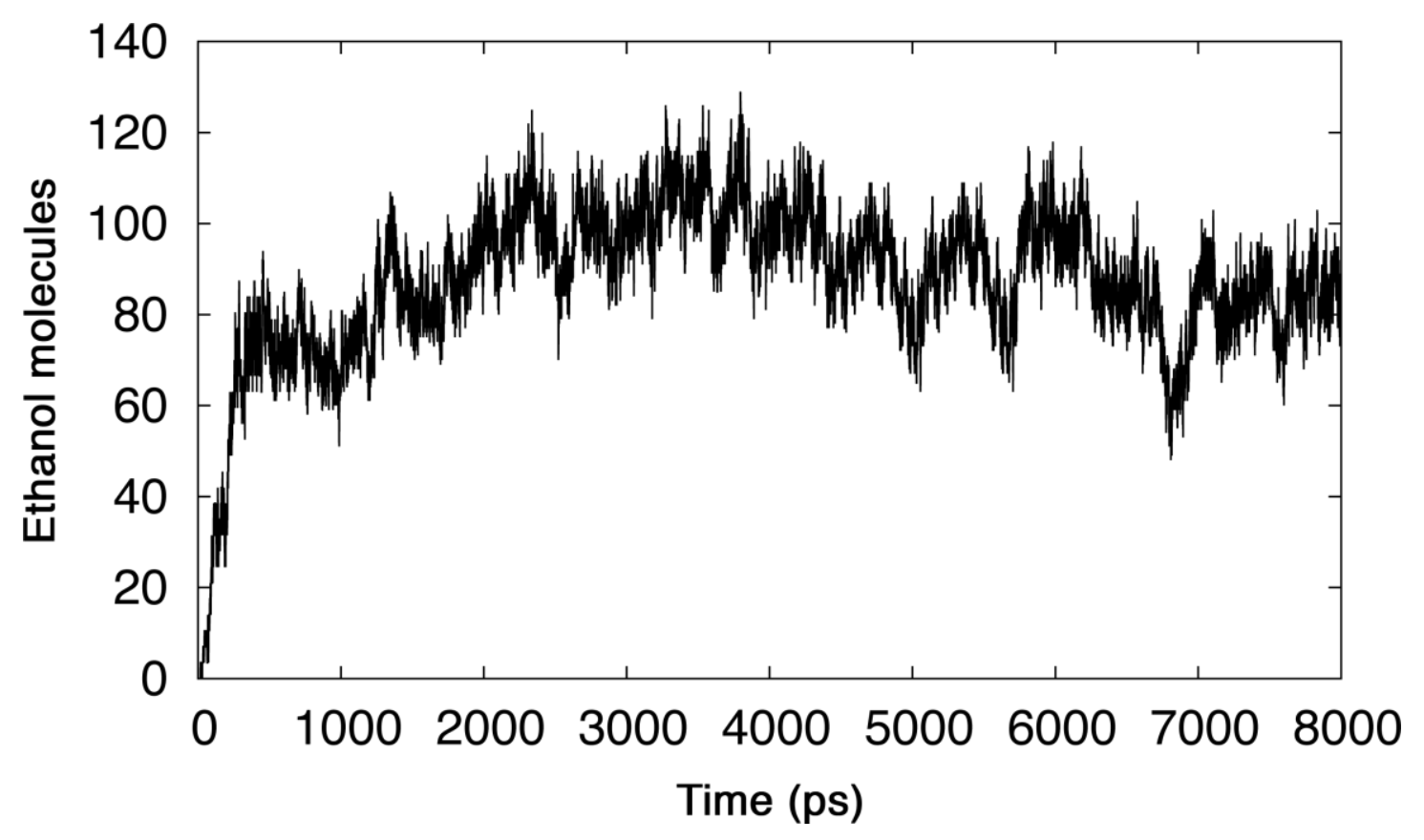


Figure S18

$\mathrm{d}\left[\mathrm{GGG}(\mathrm{TTAGGG})_{3} \mathrm{~T}\right]$
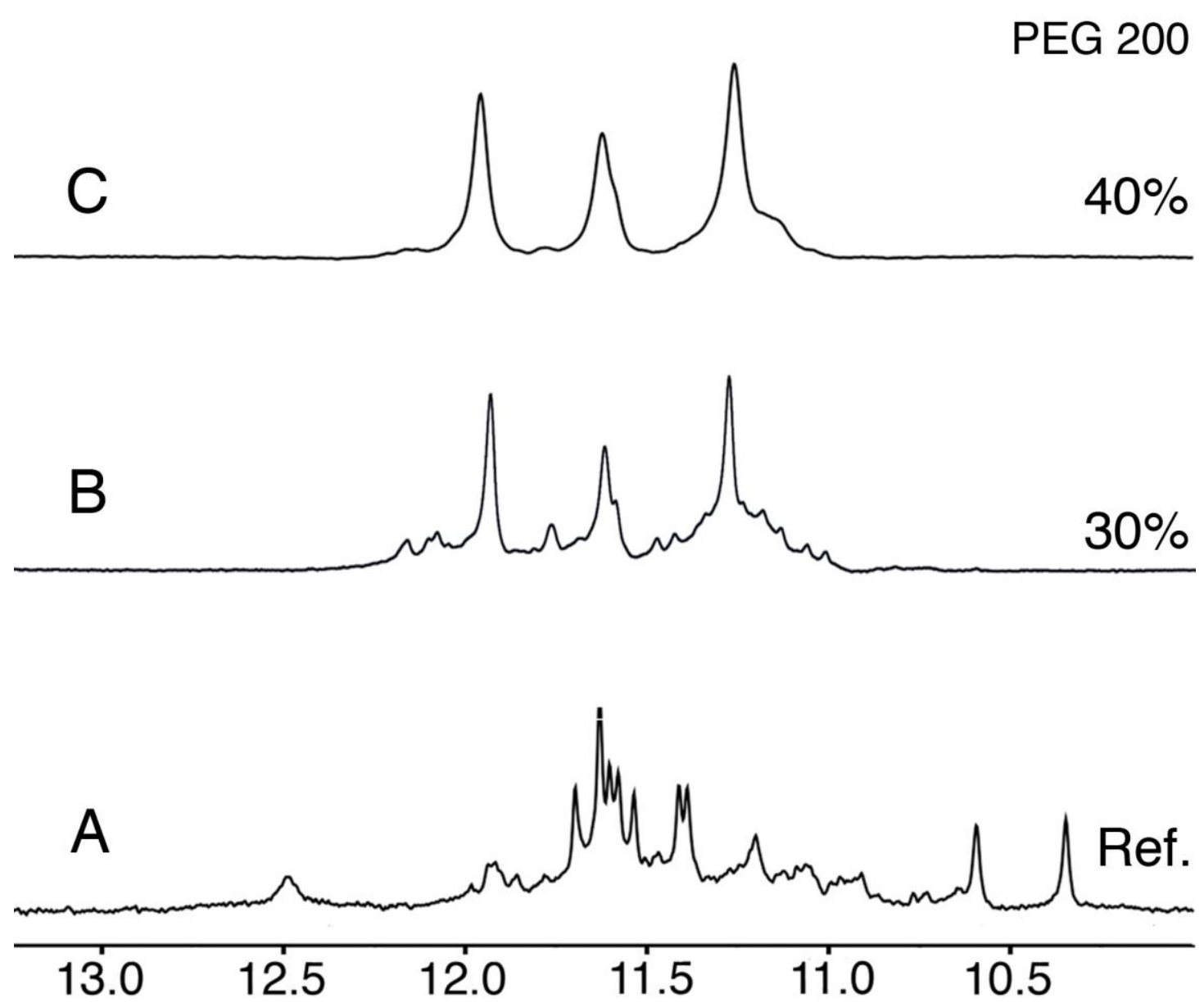
Figure S19

$$
\mathrm{d}\left[\mathrm{TAGGG}\left(\mathrm{TTAGGG}_{3}\right]\right.
$$
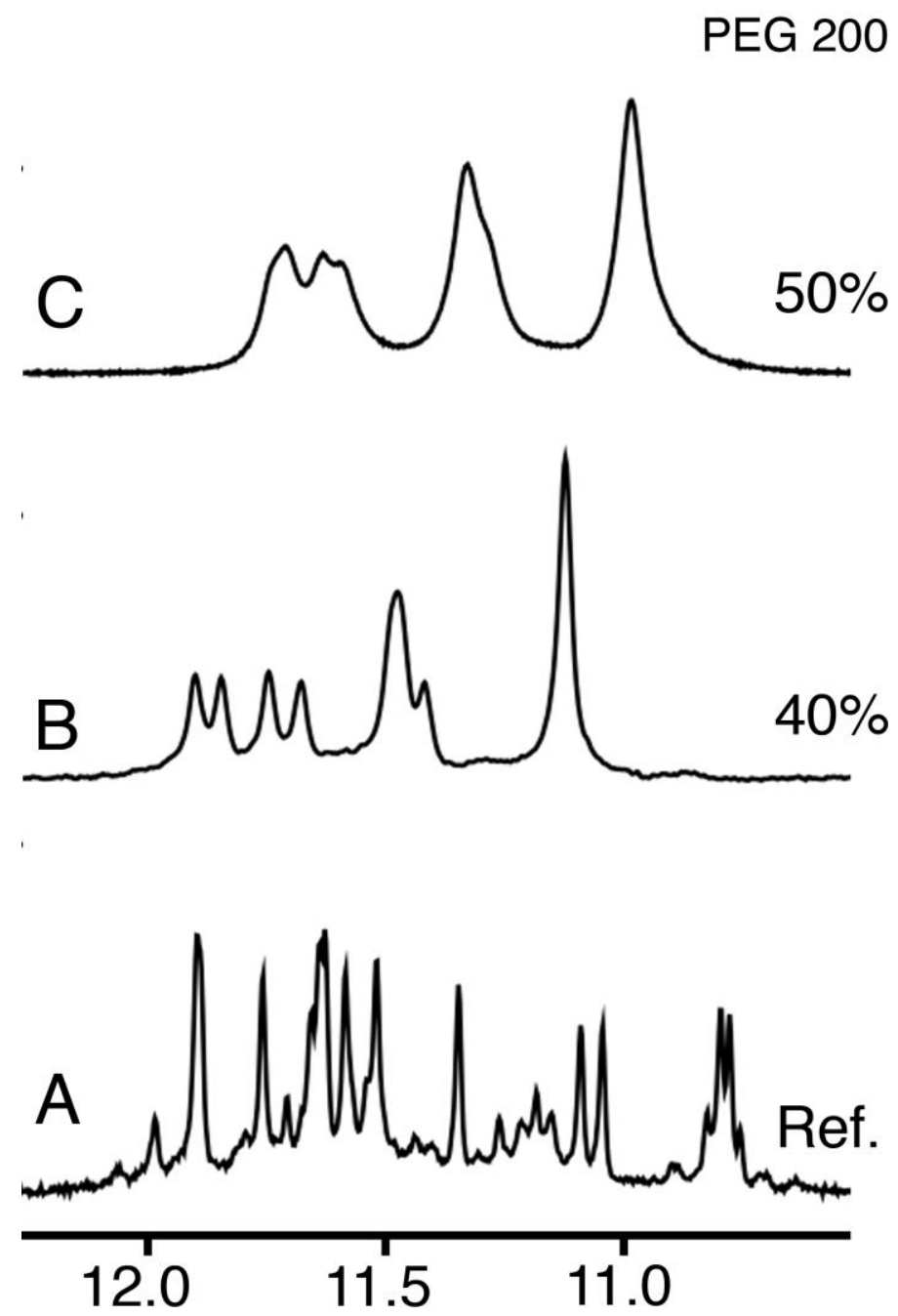
Figure S20

$\mathrm{d}\left[\mathrm{TAGGG}(\mathrm{TTAGGG})_{3} \mathrm{TT}\right]$
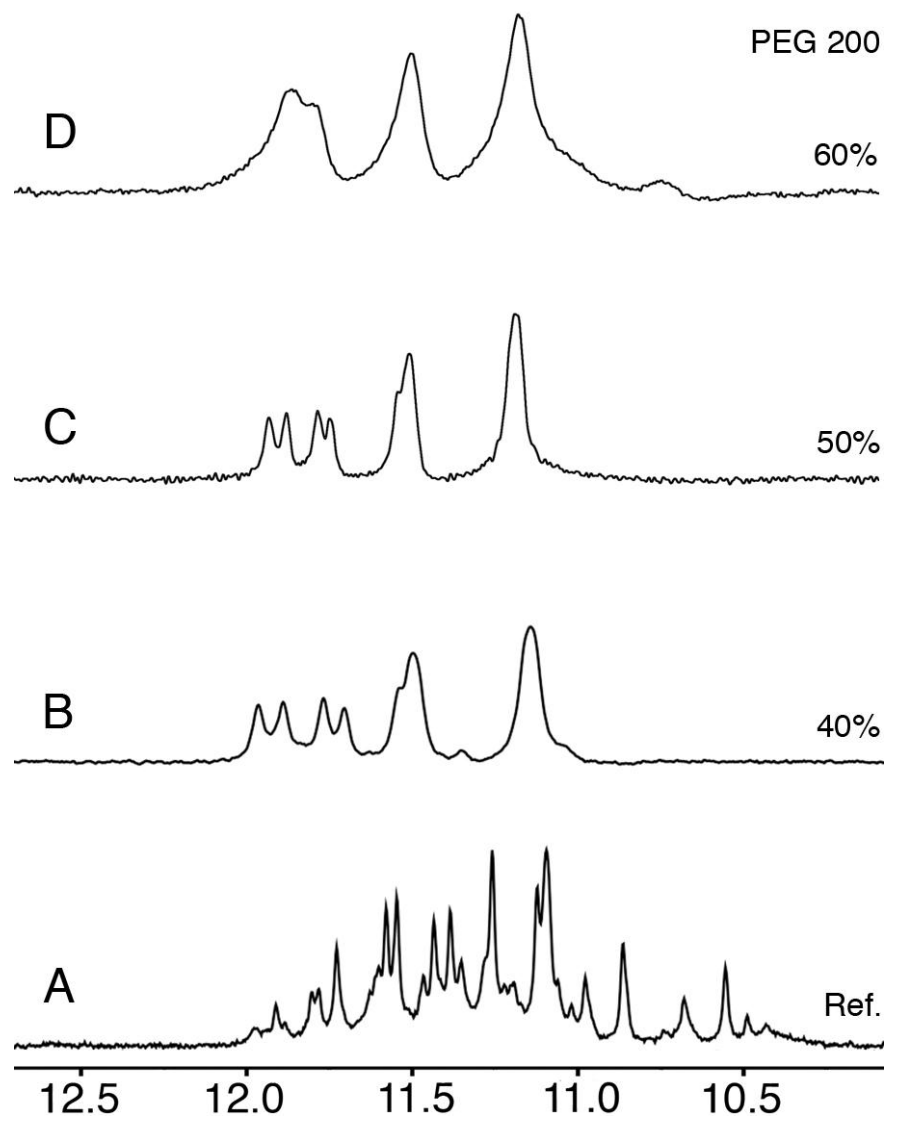
Figure S21

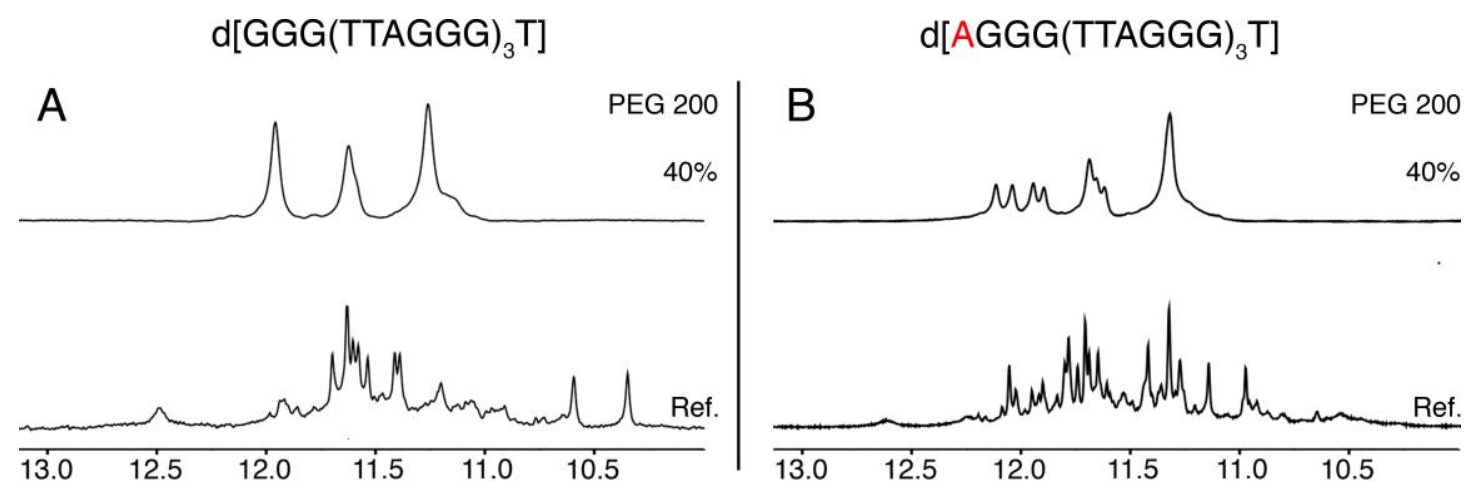

